\title{
Innovative Healthcare Delivery: the Quest for Effective Telemedicine-based Services
}

\author{
Laura Bartoli, Emanuele Lettieri and Cristina Masella \\ Department of Management, Economics and Industrial Engineering, \\ Politecnico di Milano, Milan, \\ Italy
}

\section{Introduction}

Healthcare is a complex industry that is facing great changes in its structure, organization, service delivery and operations. One of the most impactful trends for healthcare is probably the progressive ageing of population. It creates pressures in many ways, such as reducing the pool of economically active population, posing growing problems of compliance to medication and lifestyle guidance, and increasing the number of elderly people in need of long-term care and assistance. This entails increasing costs for healthcare, in a time when the availability of both economic and human resources is decreasing (Whitten et al., 2010). Within this context, the development of new paradigms of healthcare delivery that may be sustainable over time has become an imperative (Forbes \& While, 2009).

With this regard, technology has drawn increasing attention as one of the emerging service delivery vehicles running on the information highway (Zajtchuk, 1996). In fact, also a cursory review of literature would identify that Information and Communication Technology (ICT) is commonly considered a major enabler for the innovation of healthcare delivery. Despite this enthusiasm, less is understood about how to make these changes factual. Technology alone, in fact, is not enough, but is the interplay of technical and organizational factors in designing and implementing technologies that lead to improved outcomes (Obstfelder et al., 2007). In this view, a sustainable technology-based healthcare service, which entails the effective introduction of the innovation into the routine processes, is mainly underpinned by human and organizational issues, and their deep interrelation with technical aspects (Gagnon et al., 2005; Aas, 2001).

To this extent, and within the care innovation context, the use of ICT to support delivery of healthcare over a distance, namely "telemedicine" (Lehoux et al., 2002), was often mentioned as a shift in paradigms, which impacts on task design and delivery processes (de Bont \& Bal, 2008; Gagnon et al., 2005). The assessment of telemedicine-based services has often highlighted the effects of these new technologies on quality, accessibility and service costs (Gagnon et al., 2008). However, although many demonstration projects have presented evidence about clinical benefits, cost effectiveness and high levels of patient satisfaction (Whitten et al., 2010), some of them yet failed to become part of everyday clinical routine (de Bont \& Bal, 2008). This is because telemedicine-based services have been mainly considered 
as a "black box", which moves on a linear trajectory from design to diffusion (Timmermans, 2003), rather than a system in which human participants and/or machines perform work using information, technology, and other resources (namely "work systems"). Handling these latter complex, heterogeneous factors, which are expressed in controversies and solved through social negotiation, are keys to draw on effective telemedicine-based services, i.e. "sustainable work systems" (Obstfelder et al., 2007).

This challenge grounds into the largely acknowledged literature of Socio Technical Systems, which assumes that scientific knowledge and technology do not evolve in a vacuum. Rather, they should be seen as parts of the social world, being shaped by it, and simultaneously shaping it (Obstfelder et al., 2007). According to this research stream, a work system can be assumed as sustainable when it is able to function in its environment and achieve economic or operational goals over time (Docherty et al., 2002). Indeed, not only it preserves the resources it utilizes, but actually supports their growth and development.

This approach is particularly meaningful as lens of analysis because it allows to get insights that may be hard to acquire through other approaches. Despite the recognized general impact of telemedicine in healthcare delivery and the political willingness to promote it in public healthcare, in fact, previous telemedicine projects did not communicate the whole story about what is needed to make telemedicine-based services effective (Obstfelder et al., 2007). On the contrary, they mainly focused on the outcomes of clinical trials, while a limited attention was posed on the conditions, operating within the work system, which are important for the enhancement of these outcomes. Because of this gap in the literature, particularly interesting are those projects which draw on the characteristics a telemedicinebased service needs to nurture to be a sustainable work system. These projects, in particular, leaned on the belief that decisions about the care of individual patients within single structures should be based on the conscientious, explicit, and judicious use of current best evidence. This means that individual expertise should be integrated with the best information from scientifically-based and systematic research, and applied in light of each patient's values and circumstances. This approach leverages on an international political consensus. Recently, in fact, the US Congress too highlighted the need to establish standards and processes "that yield credible, unbiased, and understandable syntheses of the available evidence" about clinical practices effectiveness (IOM, 2008).

Within this context, the Italian Ministry of Health promoted a National Research Project which deepened the characteristics of telemedicine-based services for patients affected by Chronic Obstructive Pulmonary Disease (COPD).This disease, according to the data provided by the Global Initiative for Chronic Obstructive Lung Disease (www.goldcopd.it), is the $5^{\text {th }}$ cause of death in the world. Symptoms increases with the age, and the prevalence of the pathology enhances the $50 \%$ in male smokers older than 60 . In 2002, cost related to COPD enhanced 32 billion of dollars in US. This pathology is still widely under-estimated, even if its incidence keeps increasing from the $80 \mathrm{~s}^{\prime}$.

On the basis of the findings gathered through this National Research Project, the chapter is organized as follows. The next section will illustrate the specific objectives of this study and the methodology adopted to enhance them. Then, the conceptual framework and the results will be reported to show the solutions adopted in terms of sustainable work system within telemedicine-based services in the Italian context. The last section presents a discussion, the conclusions and the main directions for future research. 


\section{Research objective and methodology}

The research adopted an explanatory approach that aimed at knowing what works in telemedicine. In particular, the design principles that an effective telemedicine-based service needs to entail to introduce a sustainable work system are deepened. We focused the attention on the Italian context, considering health policy as a contextual factor. The healthcare context, in fact, is widely impacted by regulations. Moreover, when the research moves from the clinical outcomes to the organizational impact, international benchmarking and comparison become more difficult. For clarity, the main characteristics or the Italian National Healthcare System are reported in Fig. 1.

The potential generalization of our findings will be presented in the "Discussion" section.

The Italian National Healthcare System (NHS) is characterized by an universal tax-based coverage with free access to all Italian citizens and legal immigrants. Patients' co-payment is limited, despite it is increasing year after year. The NHS is organized at three levels: national, regional and local. The national level is responsible for ensuring the strategic objectives and the fundamental operating principles. The Regional Governments with their regional health departments are responsible for ensuring the delivery of a package of services through a network of Local Health Agencies, General Practitioners (GPs) and public or private accredited hospitals. Prices are based on Diagnostic Related Groups.

Fig. 1. Characteristics or the Italian National Healthcare System

In order to investigate the Italian telemedicine-based services for patients affected by COPD nationwide, an effort has gone into including the active and constant involvement of both the practitioners and the researchers in framing the research agenda, selecting and pursuing methods, and developing the implications for action. In particular, the continue attempt to learn from experience and the accumulation of knowledge over time resulted in the development of theoretical evidence for researchers and practical wisdom for practitioners (Pasmore et al., 2008).

Following this research approach, results were achieved in two sequential steps. First, the researchers, coached by expert practitioners, conducted a review of the literature and a survey throughout the Italian Pulmonary Hospital Departments in order to identify the most relevant experiences of Italian telemedicine-based services for COPD patients. In contrast to quantitative research, which often makes use of random samples, our sampling for qualitative research had to be purposive (Lijphart, 1971). Second, an analysis of the selected telemedicine-based services was conducted. The sampling was empirical (Yin, 1984), and selected cases were both the most relevant and most paradigmatic. The analysis these cases were conducted by means of a holistic multiple cases-design (Yin, 1984) in order to develop rich and accurate insights that may be hard to acquire through other research designs (Lijphart, 1971).

\subsection{Data collection}

Because of the explanatory nature of the research, and according to the limited number of professionals usually employed in the delivery of the service, the key informants have been carefully individuated for face-to-face interviews. In particular, 11 physicians and 5 nurses were selected with respect to six relevant cases. They were all responsible of developing the 
service, and thus they had been more widely exposed to the change rather than colleagues. Key informants were asked to discuss about the main design principles the telemedicinebased service entails, and which organizational levers have been introduced to render the work system sustainable. Questions concerning the service backsides and the weaknesses have been asked too. Finally, information about the interviewee background were collected to better illuminate her/his perspective.

Interviews were semi-structured grounding on the research framework, and they lasted 150 minutes as average. Information gathered through face-to-face interviews were integrated with secondary-sources data. In particular, business process documentations, performance data reports, technical information system documentation, unpublished management reports, administrative guidelines, jurisdictional papers and fields' notes were analyzed to gather an overview of the processes. In fact, data triangulation from multiple informants and data sources enhances objectivity (Mitroff, 1972), mitigates potential bias (Miller et al., 1997; Huber \& Power, 1985) and helps developing converging lines of enquiry (Patton, 2002).

\subsection{Data analysis}

Every interview was transcript and sent back to the interviewee for validation. Afterward, validated information and supplementary data were utilized to build individual case studies. Follow up information was used to clarify events and resolve discrepancies. Next, the cross-cases analysis began. It aimed at developing consistent patterns of the theoretical relationships across the cases (e.g., Gilbert, 2005; Eisenhardt, 1989). Once the cross-cases analysis was underway, researchers cycled among theory, data and the literature to adjust emerging construct definitions, abstraction levels, construct measures and theoretical relationships. This cycling process continued until a strong match between the case data and theory was achieved across most (sometimes all) of the cases.

\section{Conceptual framework}

The research adopts the notion of work system to capture the essence of a telemedicine-based service. In particular, a "work system" has been defined as "a system in which human participants and/or machines perform a business process using information, technology, and other resources to produce products and/or services for internal or external customers" (Alter, 2004: 321). This perspective represents a particularly meaningful lens of analysis to study telemedicinebased services because it digs into the relationships between technology, work context and organizational activities from a social and organizational perspective (Niccolini, 2005). In particular, this perspective is precious to analyze the controversies which always arise when a new technology is implemented (Obstfelder et al., 2007). To highlight the design principles an effective telemedicine-based service needs to entail, the concept of sustainable work system has been introduced. In particular, a sustainable work system is a system where human and social resources are regenerated through the process of work while still maintaining productive and competitive forms (Docherty et al., 2002). That is, the ability of a system to regenerate the resources that employs and the incentives that change behaviors and goals.

The analysis of sustainable work systems requires a comprehensive guiding framework for action (Docherty et al., 2008). Acknowledging the increased pace and complexity of change, and reconciling some of the conundrums and criticisms of the traditional organizational and 
change management research streams, we referred to organizational agility principles (de Bont \& Bal, 2008) to investigate the design characteristics a telemedicine-based service should entail in order to be sustainable. Frameworks based on agility are in fact a suitable guidance to analyze sustainable work systems (Worley \& Lawler, 2009). In particular, instead of trying to specify the criteria of effectiveness, agility models describe the design features that are necessary to deliver on a sustainable work system, which are (1) a maximum surface area structure; (2) transparent information and decision-making processes; (3) flexible performance management systems; and (4) clear human capital strategies (Worley \& Lawler, 2009).

These principles have been conceptualized in order to gather evidence with respect to our specific work system (i.e. a telemedicine-based service).

First, work systems adopt structures that maximize the "surface area" of the firm by connecting as many employees as possible with the external environment. Organizations that accomplish this increase the external focus of their members. A variety of companies have increased their surface area by adopting process-based or network structures, which increase the centrality of customer (Galbraith, 2005). Drawing on telemedicine-based services, this aspect highlights the need to develop work systems based on services networks. Any tensions between goals in primary and secondary care need to be handled with care, and patientcentric approach needs to be developed (Obstfelder et al., 2007; Aas, 2001).

Second, work systems need to adopt transparent information systems and decision-making processes. This widely available information allows everyone throughout the work system to make customer-related decisions, moving decision-making to wherever decisions can best be made and implemented. Adopting this principle within telemedicine-based services, this renders nurses more autonomous in decision-making, producing the redistribution of tasks and workload within the clinical team. The adoption of transparent information systems, in fact, might empower nurses able to handle most cases autonomously, asking for doctors' consult only in exceptional cases. This not only underpins the delegation of medical tasks to non-medical personnel (Niccolini et al., 2005), but it even allows patients to improve their self monitoring attitude, rendering them and caregivers active partners in the disease management.

Third, work systems need to adopt flexible talent management and reward systems. Accordingly, a focus on human capital strategies is incentivized, and people are encouraged to find out what needs to be done instead of waiting for someone who tells them about their tasks. In this context, the need to invest in the development of operators' skills and competencies is mandatory. The concerns that arise from the interplay of new technology with existing professional practices, in fact, go beyond simple training issues. The literature about telemedicine-based services, for example, remarks that a critical issue that healthcare professionals encounter when new technologies need to be integrated into routine service delivery is that the technology often undermines the previous professional security and credibility, and arises some concern about the possibility to replace professionals with technologies. This issue is particularly severe for nurses, since their previous consolidated relationships with doctors and healthcare assistants have to change (Hibbert et al., 2004). Work system designers need to deal with these challenges, investing in a strengthening of competences which will reassure professionals.

Finally, work system needs to invest to nurture a highly motivated and satisfied workforce. Organizations utilize a variety of reward practices, including bonuses, stocks, and "person based pay". However, interventions based on extrinsic motivation are often problematic and 
ineffective, because it is difficult to link performances and financial incentives (Kohn, 1993). These findings suggest the need to adopt "softer" approaches that work through intrinsic motivations. In particular, it is widely accepted that healthcare professionals should be motivated by larger themes of social responsibility, public trust, teamwork and civic virtue (Wynia, 2009).

The conceptualization of our framework is reported in Table 1.

\begin{tabular}{|c|c|}
\hline $\begin{array}{l}\text { Agility models design principles } \\
\text { (Worley and Lawler, 2009) }\end{array}$ & $\begin{array}{c}\text { Sustainable work system design } \\
\text { principles for an effective telemedicine- } \\
\text { based service }\end{array}$ \\
\hline $\begin{array}{l}\text { Maximize the surface area structure: } \\
\text { Work systems adopt structures that } \\
\text { maximize the "surface area" of the firm by } \\
\text { connecting as many employees as possible } \\
\text { with the external environment. It entails } \\
\text { the adoption of network structures and } \\
\text { customer-based processes. }\end{array}$ & $\begin{array}{l}\text { Coordination: } \\
\text { The maximization of the "surface area" } \\
\text { aims at weakening tensions between goals } \\
\text { and practices in primary and secondary } \\
\text { care, developing and diffusing a patient- } \\
\text { centric approach. }\end{array}$ \\
\hline $\begin{array}{l}\text { Transparent information and decision- } \\
\text { making processes: } \\
\text { Work systems need to adopt transparent } \\
\text { information systems and decision-making } \\
\text { processes to allow everyone to make } \\
\text { customer-related decisions, moving } \\
\text { decision-making to wherever decisions can } \\
\text { best be made and implemented. }\end{array}$ & $\begin{array}{l}\text { Workload distribution: } \\
\text { The adoption of transparent information } \\
\text { systems allows the delegation of medical } \\
\text { tasks to non-medical personnel. The easier } \\
\text { access to information, in fact, renders } \\
\text { nurses more autonomous in decision } \\
\text { making, and patients more aware in self- } \\
\text { monitoring. It entails the redistribution of } \\
\text { tasks and workload. }\end{array}$ \\
\hline $\begin{array}{l}\text { Flexible performance management } \\
\text { systems: } \\
\text { Work systems need to adopt flexible talent } \\
\text { management and reward systems, focusing } \\
\text { on human capital strategies. }\end{array}$ & $\begin{array}{l}\text { Competences: } \\
\text { Investments and actions aimed at } \\
\text { strengthening competences are needed, } \\
\text { especially for reassuring professionals } \\
\text { about their role in service delivery. }\end{array}$ \\
\hline $\begin{array}{l}\text { Clear human capital strategies: } \\
\text { Work system needs to invest to nurture a } \\
\text { highly motivated and satisfied workforce. }\end{array}$ & $\begin{array}{l}\text { Satisfaction: } \\
\text { Softer approaches should be preferred to } \\
\text { financial incentives to enhance operators' } \\
\text { satisfaction. }\end{array}$ \\
\hline
\end{tabular}

Table 1. The conceptual framework

\section{Results from the survey: the selection of the most relevant experiences}

A survey throughout the Italian Respiratory Hospital Departments has been conducted to identify the relevant Italian telemedicine-based services for patients affected by COPD. 240 questionnaires were sent, with a satisfactory answer rate about 44\%. 26 telemedicine-based services were identified. The $50 \%(n=13)$ of them were conducted within non-teaching hospitals, the $19 \%(n=5)$ in territorial hospitals, the $19 \%(n=5)$ in a Scientific Institutes for Research, Hospitalization and Health Care (namely IRCCS), and the $12 \%(n=3)$ in teaching hospitals (Fig. 2). This variety highlights that experiences are very heterogeneous among 
them. Moreover, eleven were ongoing (42\%), eight (31\%) were concluded and seven were on the initial stage (27\%) (Fig. 3). Collected data highlight telemedicine-based services are wide spreading, and although several projects started, only some of them were introduced into a routine. It confirms that discussions concerning telemedicine-based services are getting pivotal, and both the description of the state of art and arguments about what does really works are getting mandatory. This information, in fact, is key for policy makers, who are asked to take decisions concerning the topic.

Since we aimed at deepening how to get telemedicine-based services effective, referring to the design principle a work system need to entail for a sustainable introduction of the innovation into the routine processes, we will focus on ongoing projects. Accordingly, additional information was retrieved with respect to the stage of maturity enhanced by the ongoing experimentations. Results are reported in Fig. 4.

The six institutionalized telemedicine-based services were selected for a further and deeper analysis. More mature services, in fact, have more to say concerning the design principles a work system needs to entail to be sustainable over time. The reason is twofold. First, these projects officially entered into the routine of organizations. Accordingly, they express processes and work systems which have been accurately thought, shared, designed and

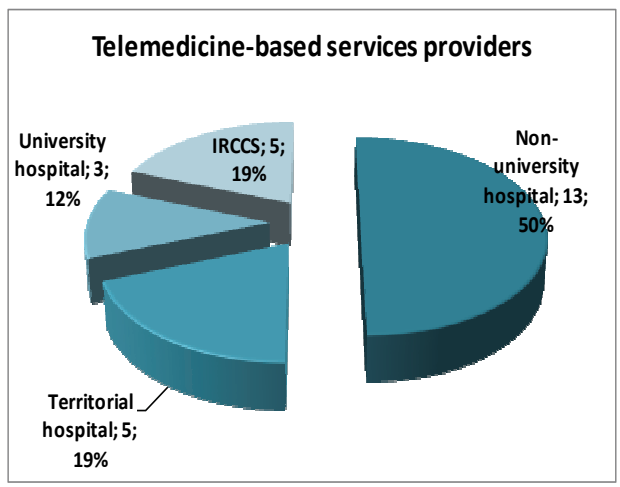

Fig. 2. The services providers

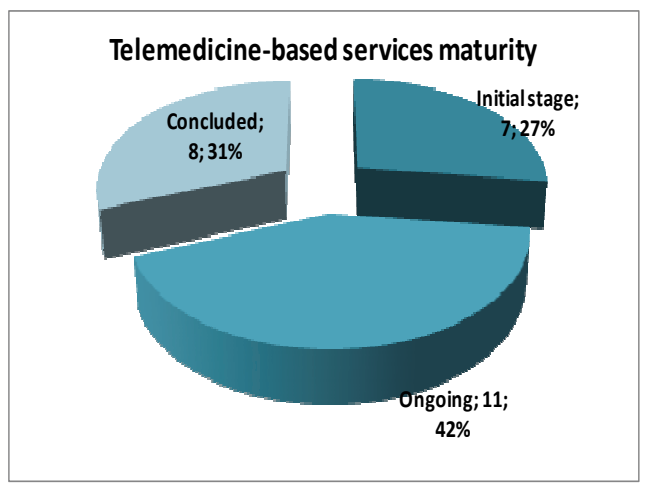

Fig. 3. The services maturity 


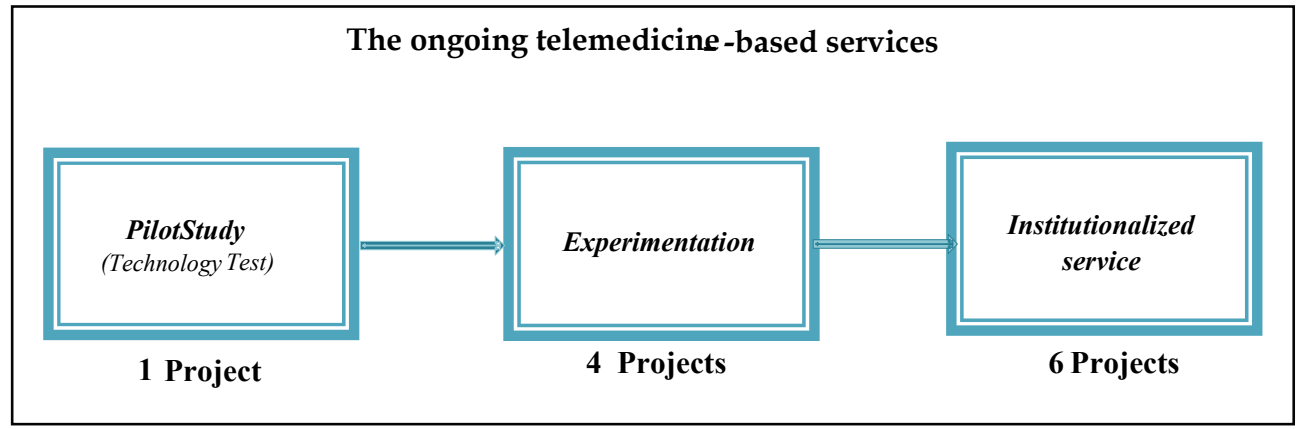

Fig. 4. The services state of art

organized by operators and management, before being introduced. Second, these services, have been running for a number of years, often being pilot projects or experimentations before than institutionalized services. Accordingly, they have had the possibility to pass trough incremental improvements pathways before being institutionalized.

These two arguments characterize institutionalized services as a richer and more complete empirical setting for the scope of our analysis. Accordingly, they have been preferred to others for a deeper analysis.

\section{Results from the case studies}

An in-depth analysis of the six institutionalized telemedicine-based services has been conducted. Results gathered through the six explanatory case studies are reported. In particular, first a brief characterization of the healthcare organization which hosted the telemedicine-based service is highlighted. Second, a description of the services provided is conducted. Third, a short picture of the evolution of the service and a report of the main characteristics of the enrolled patients is stated to offer a wider overview concerning the results. Finally, a discussion on the lever adopted to enhance a sustainable work system, and indeed an effective telemedicine-based service, is shown, following the principle designs highlighted in the framework.

A synthesis of the main characteristics of the projects are reported in Tab. 2

\subsection{Case 1}

The first project is provided by the Respiratory Department of a non-university hospital of the Northern Italy ( 30 beds, 9 physicians).

The organization design: which services are provided and how

The telemedicine-based services provided are the following:

Telemonitoring: a technologic device records the patients' main vital parameters during the night (blood pressure, pulse and saturation). The outline is then automatically sent viatelephone to the referential hospital physician. Routinely, the specialist examines the parameters and sends the medical report back to the patient via e-mail. The frequency of the transmission of data is scheduled patient by patient, according to his/her clinical conditions. In case of out-of range parameters, the physician can (i) go with his/her staff to the patients' home, (ii) contact the LHA staff for a domiciliary visit or (iii) alert the Hospital Emergency Department service. 


\begin{tabular}{|c|c|c|c|c|c|}
\hline \multirow[b]{2}{*}{ Case } & \multirow{2}{*}{$\begin{array}{c}\text { Telemedicine- } \\
\text { based services } \\
\text { provided }\end{array}$} & \multirow[b]{2}{*}{$\begin{array}{l}\text { Telemedicine-based } \\
\text { Services Main Goals }\end{array}$} & \multicolumn{2}{|c|}{ Patients } & \multirow[b]{2}{*}{$\begin{array}{l}\text { Main Actors } \\
\text { involved }\end{array}$} \\
\hline & & & $\begin{array}{l}\text { Number } \\
\text { (as yearly } \\
\text { average) }\end{array}$ & Typology & \\
\hline 1 & $\begin{array}{c}\text { Telemonitoring; } \\
\text { Teleconsulting }\end{array}$ & Home hospitalization. & 20 & $\begin{array}{l}\text { Seriously } \\
\text { severe }\end{array}$ & $\begin{array}{l}\text { Hospital } \\
\text { physicians; } \\
\text { LHA staff }\end{array}$ \\
\hline 2 & Telemonitoring & $\begin{array}{l}\text { Follow up of ambulatory } \\
\text { patients. }\end{array}$ & $15-60$ & $\begin{array}{l}\text { Quite } \\
\text { severe }\end{array}$ & $\begin{array}{l}\text { Hospital } \\
\text { physicians; } \\
\text { Call Center } \\
\text { operators }\end{array}$ \\
\hline 3 & $\begin{array}{l}\text { Telemonitoring; } \\
\text { Telenursing }\end{array}$ & $\begin{array}{l}\text { Follow up of ambulatory } \\
\text { patients; } \\
\text { Overcoming of } \\
\text { geographical barriers. }\end{array}$ & 30 & Severe & $\begin{array}{l}\text { Hospital } \\
\text { Nurses }\end{array}$ \\
\hline 4 & \begin{tabular}{r|} 
Telemonitoring; \\
Teleconsulting
\end{tabular} & $\begin{array}{l}\text { Follow up of ambulatory } \\
\text { patients; } \\
\text { Overcoming of } \\
\text { geographical barriers. }\end{array}$ & 100 & Severe & Hospital nurses \\
\hline 5 & $\begin{array}{l}\text { Telemonitoring; } \\
\text { Teleconsulting }\end{array}$ & Home hospitalization. & 160 & $\begin{array}{l}\text { Severe/ } \\
\text { seriously } \\
\text { severe }\end{array}$ & $\begin{array}{l}\text { Hospital } \\
\text { nurses; } \\
\text { LHA staff }\end{array}$ \\
\hline 6 & $\begin{array}{c}\text { Telemonitoring; } \\
\text { Teleconsulting }\end{array}$ & Home hospitalization. & 240 & $\begin{array}{l}\text { Severe/ } \\
\text { seriously } \\
\text { severe }\end{array}$ & $\begin{array}{l}\text { Hospital team; } \\
\text { GPs }\end{array}$ \\
\hline
\end{tabular}

Legend: LHA: Local Health Agency, GP: General Practitioner

Table 2. The cases

Teleconsulting: the home-assisted patients have the possibility to contact directly the referring specialist in case of a perceived worsening of symptoms. The specialist knows personally each patient and his/her clinical conditions. Accordingly, the physician can understand more easily the situation, and intervene in a more effective and quick way.

Since the service is not available out of the service hours, potential emergency interventions remain under the responsibility of the Hospital Emergency Department.

\section{Evolution of the service and patients enrolled}

An institutionalized telemedicine-based service has been running since 2006. Nine clinicians and two nurses are involved in the service delivery. The number of patients enrolled in the program is 20 as average. This number is not destined to grow. Each specialist is the referent for from 1 to 3 patients. To this concern, the responsible of the service believes that following a limited number of patients preserves a correct relationship patient-clinician, which represents a crucial element in the care of chronic illnesses, because the awareness and knowledge of the clinical situation of every patient increases the effectiveness of the interventions.

Patients are enrolled within the hospital district. Since it has an extension of 30 kilometers as averages, the possibility for the hospital staff to suddenly intervene when required is guaranteed. 
Enrolled patients are in extremely serious clinical conditions: they are in a severe stage of COPD, ventilated or tracheostomized, interested by highly weakening co-morbidities (i.e. Amyotrophic Lateral Sclerosis -ALS-). Given these severe patients' conditions, the service aims at giving them the opportunity to be de-hospitalized and live in their own houses with the same level of safety that a hospitalization would assure.

The organizational levers adopted to enhance a sustainable work system

The major lever utilized to render the work system sustainable is the definition of an interorganizational business model, which coordinates the hospital team and the Local Health Agency (LHA) operators in the conjunct provision of the telemedicine-based service.

The definition of an inter-organizational business model

An inter-organizational business model, which coordinates the hospital team and the Local Health Agency operators, underpins the provision of the service. In particular, the hospital team, mainly physicians, tele-monitors patients' conditions and is responsible for handling acute events. The Local Health Agency (LHA) staff, instead, manages the technology supply and the delivery of general home care assistance. The coordination between hospitals and LHAs came out being an enabling factor to enhance a sustainable service: it allows an easier definition of shared strategies between secondary and territorial healthcare facilities, and a more coherent human resources management.

The actual organization of the service is perceived as positive from the physicians' point of views because it allows them to follow up patients even if they are not hospitalized. Caregivers are satisfied too, because they become more aware with respect to how to handle the patients' clinical conditions. On the contrary, nurses reported they are not satisfied with the provision of the service. This latter represents the real backside of this service delivery. This un-satisfaction is related to the fact that they do not play an active role in the management of the service. In particular, they intervene only when the specialist asks them to perform a specific intervention at domicile. Moreover, they do not receive any additional remuneration for the service provision. The scarce involvement of nurses is endurable only because the service is dedicated, on purpose, to a limited number of patients.

A summary of how the utilized lever impacts on the sustainable work system design principles to enhance an effective telemedicine-based service is reported above (Tab. 3).

\begin{tabular}{|l|l|}
\hline$\underline{\text { Coordination }}$ & $\begin{array}{l}(+) \text { the structured coordination between LHA and hospital enables a } \\
\text { wider contact between the clinical team and the territory. }\end{array}$ \\
\hline$\underline{\text { Workload }}$ & $\begin{array}{l}(+) \text { the structured business model between LHA and hospital enables a } \\
\text { better distribution of tasks and responsibilities; } \\
(-) \text { the enrollment of a limited number of patients is key to maintain the } \\
\text { work system sustainable. }\end{array}$ \\
\hline$\underline{\text { Competences }}$ & $\begin{array}{l}(+) \text { thanks to the direct and constant relationship with the physicians, } \\
\text { caregivers become more aware with respect to how to handle patients' } \\
\text { conditions. }\end{array}$ \\
\hline Satisfaction & $\begin{array}{l}\text { (+) caregivers are satisfied because they acquire a better and more aware } \\
\text { knowledge of how to handle the pathology; } \\
(+) \text { the clinical staff has the chance to better follow up chronic patients, } \\
\text { without hospitalize them; } \\
(-) \text { nurses are not satisfied because no new incentives have been } \\
\text { introduced, even if they partly participate to the new service delivery. }\end{array}$ \\
\hline
\end{tabular}

Table 3. Synthesis of the Case 1. 


\subsection{Case 2}

The second project is provided by the Respiratory Department of a territorial hospital of the Northern Italy (5 physicians, 3 nurses and 2 socio-assistant operators).

The organization design: which services are provided and how

The service provided is described above.

Telemonitoring: a technologic device records the patients' main vital parameters during the night (blood pressure, pulse and saturation). At predefined cadence, an operator of the Call Center of the Technologic Service Provider calls the patient to both (i) asks some defined questions regarding his/her general conditions; (ii) allows the transmission of data previously recorded. Afterward, the caller uploads the file resulting from the interview in a server, and sends it to the physician. The clinician examines the outline (both clinical data and answers to a questionnaire), being helped by a meaningful interface in detecting potential suspicious values. In case of out-of-range parameters, the physician contacts the patient and defines the interventions required, which may imply the intervention of the GP, the physician's visit at the domicile or a predating of the ambulatory visit.

Evolution of the service and patients enrolled

The project started two years ago (2008), and nowadays it counts 15 enrolled patients. Because of the success of the initiative, in 2011 the number of patients enrolled will grow to 60.

Patients live within the district, are personally known by the two involved physician, and are in quite severe but stable clinical conditions.

The organizational levers adopted to enhance a sustainable work system

The major lever utilized to render the work system sustainable is the definition of the direct involvement of the Call Center of the Technologic Service Provider in the provision of the service.

\section{Involvement of the Call Center of the Technologic Service Provider}

The Call Center of the Technologic Service Provider plays a key role in the delivery of the service. It allows the two physicians involved to have a higher visibility on patients' progression of the pathology, keeping the workload burden affordable. Accordingly, physicians consider themselves satisfied with the service. Patients are satisfied too, because they acquire a better knowledge and awareness concerning their pathology and its evolution. However, some of them expressed discomfort about the intrusiveness of the operator of the Call Center, and others decided to abandon the service since they felt that the personal relationship with the specialists was diminishing.

According to these service delivery models, it has to be highlighted that nurses are not involved at all, while the coordination with the territory is facilitated by the fact that the hospital is a presidium of the LHA.

To sum up, a scheme of how the utilized lever impact on the sustainable work system design principles to enhance an effective telemedicine-based service is reported above (Tab. 4).

\subsection{Case 3}

The third project is provided by the Respiratory Department of a territorial hospital of the Central Italy ( 5 physicians, 6 nurses, 2 socio-assistant operators, 1 bed for day-hospital treatments). The territory under discussion is particularly suited for home care delivery through telemedicine, since it is mountainous, with little towns scarcely populated. Accordingly, travelling is difficult and public transportations insufficient. 


\begin{tabular}{|c|c|}
\hline$\underline{\text { Coordination }}$ & $\begin{array}{l}(+) \text { the coordination with the territory (i.e. GPs) is facilitated by the fact that the } \\
\text { hospital is a presidium of the LHA. }\end{array}$ \\
\hline $\begin{array}{l}\text { Workload } \\
\text { distribution }\end{array}$ & $(+)$ the involvement of the Call Center keeps the workload burden affordable. \\
\hline$\underline{\text { Competences }}$ & $\begin{array}{l}(+) \text { thanks to the direct and constant relationship with the physician, patients and } \\
\text { caregivers acquire a better and more aware knowledge of how to handle the } \\
\text { pathology. }\end{array}$ \\
\hline$\underline{\text { Satisfaction }}$ & $\begin{array}{l}(+) \text { the clinical staff has the chance to better follow up chronic patients, without } \\
\text { hospitalize them; } \\
(+) \text { thanks to the direct and constant relationship with the physician, patients and } \\
\text { caregivers acquire a better and more aware knowledge of how to handle the } \\
\text { pathology; } \\
(-) \text { the involvement of Call Center makes some patients uncomfortable since they } \\
\text { perceive the personal relationship with the specialist was diminishing. }\end{array}$ \\
\hline
\end{tabular}

Table 4. Synthesis of the Case 2.

The organization design: which services are provided and how

The main telemedicine-based services provided are two.

Telemonitoring: a technologic device records the patients' main vital parameters, and sends them to the hospital. The schedule of transmissions is defined through an accordance between the hospital nurses and the patients. When data are received, the nurse, aided by a meaningful interface, controls the outlines and, in case out-of-range parameters, contacts the domicile of the patient to understand if a specific intervention is needed. After this preliminary analysis, the nurses decided whether to alert the specialist, the GP or the emergency service.

Telenursing: following a predefined schedule, the nurses call the domicile of the patients, even if the vital parameters are regular, in order to get sure that the situation is under control. The nurses are interested in analyzing the situation under every point of view (family troubles, need for psychological help etc). Moreover, the patient/caregiver himself/herself may call a special number to talk directly with the nurses and to ask some specific questions, when needed.

\section{Evolution of the service and patients enrolled}

The service has been running since the end of the 1990s. Different organizational and institutional solutions came one after the other thus far. In the latest years, the service acquired the characteristics and functionalities above described.

Nowadays, 29 patients affected by chronic respiratory insufficiency are enrolled in the service. Patients live in the hospital district, and are in severe clinical conditions. Each of them is univocally followed by an assigned tutor nurse. Tempts to increase the number of patients enrolled are ongoing. However barriers, mainly cultural, still hinder the wide spreading of the service.

The organizational levers adopted to enhance a sustainable work system

The major lever utilized to render the work system sustainable is the empowerment of nurses.

The empowerment of nurses

The nurses of the Respiratory Nursing Ambulatory (PNA), which is a unit hosted by the hospital, play a pivotal role in patients' assistance, as they provide the tele-nursing service, 
autonomously define the patients' care plans and are responsible for the education and training of patients and/or caregivers. Because of this, nurses express great satisfaction, as their professionalism is emphasized and taken in higher consideration. This satisfaction is measured not only by the general positive mood of the professionals involved, but through quantitative data gathered through a satisfaction survey too. To nurture this sense of satisfaction, a process of continuous innovation is entailed. In particular, a budget for nurses' permanent training has been allocated by the strategic administration, and specific courses are organized every year to keep nurses and personnel updated about the treatment of the chronic illnesses.

Patients are satisfied too concerning this delivery model. In particular, they are very reassured by the fact they have a unique and dedicated interface with the hospital, i.e. their tutor nurse. Moreover, they appreciate the possibility to take advantage of the clinical assistance from their home, since for some of them it is hard to move away from home because of both their severe clinical conditions and the territorial geographical barriers.

Finally, the coordination with the territory should be assured by the fact that the hospital is a presidium of the LHA. However, the collaboration with GPs is particularly scarce. In facts, while some of them understand the importance of the service and turn out to be highly collaborative in its delivery, others mistrust the initiative and spread an unjustified skepticism among potential patients.

A synthesis of how the empowerment of nurses impacted on the enhancement of a sustainable work system is reported above (Tab. 5).

\begin{tabular}{|l|l|}
\hline Coordination & $\begin{array}{l}(+) \text { the coordination with the territory is facilitated by the fact that the hospital is a } \\
\text { presidium of the LHA; } \\
(-) \text { GPs are not always collaborative. }\end{array}$ \\
\hline$\underline{\text { Workload }}$ & $\begin{array}{l}(+) \text { the involvement of the nurses keeps the workload burden affordable; } \\
(+) \text { patients acquire a more aware access to hospitals. }\end{array}$ \\
\hline$\underline{\text { Competences }}$ & $\begin{array}{l}(+) \text { thanks to the direct and constant relationship with the nurses, patients and } \\
\text { caregivers acquire a better and more aware knowledge of how to handle the } \\
\text { pathology; } \\
(+) \text { nurses competences have been empowered through continuous training } \\
\text { programs. }\end{array}$ \\
\hline$\underline{\text { Satisfaction }}$ & $\begin{array}{l}(+) \text { the clinical staff has the chance to better follow up chronic patients, without } \\
\text { hospitalize them; } \\
(+) \text { nurses are satisfied because their professionalism has been enhanced; } \\
(+) \text { patients and caregivers are satisfied because they are a unique interface within } \\
\text { the hospital, and they avoid unnecessary trips to hospitals. }\end{array}$ \\
\hline
\end{tabular}

Table 5. Synthesis of the Case 3.

\subsection{Case 4}

The fourth project is provided by the Respiratory Departments of a network of hospitals of the Northern Italy. The service in rooted in an experimentation which aimed at increasing the access to care of low populated areas. Among the structures involved, the one with the highest number of patients enrolled has been selected for a deeper analysis. In particular, the analysis focuses on the telemedicine-based service provided by the Respiratory Department of a teaching hospital of the Northern Italy (14 physicians, 50 nurses, 62 beds, among which 25 for rehabilitative activities and 2 beds for day-hospital). 
The organization design: which services are provided and how

The main telemedicine-based services provided are two.

Telemonitoring: Patients are weekly contacted by their tutor nurse, who tells them to perform the measures of blood pressure, oxygen content and cardiac frequency. These parameters are then automatically sent to the hospital, via the Service Center Provider. Afterward, nurses ask patients a predefined questionnaire, posing questions concerning health conditions and perceptions. In case of out-of-range parameters, or critical scenario highlighted through the questionnaire, the nurse intervenes through a modify of the therapy. When the situation is considered particularly critical, the nurse contacts the specialist for a second opinion. The specialist, on his/her hand, may decide to (i) contact the GP and ask him/her to perform a visit at domicile, (ii) contact the emergency service for an immediate intervention or (iii) hospitalize the patient.

Teleconsulting: In case of perceived worsening of symptoms, patients have the possibility to directly contact their hospital tutor nurse, who, when needed, forwards the call to the physician. Hospital nurses are available for teleconsultations from Monday to Friday during the working hours. During the night and on week-ends, indeed, these teleconsultation are handled by the nurses operating in the Call Center of the Service Center Provider. Every nurse, both hospitals' and Call Center's, has access to the patients' online medical record.

\section{Evolution of the service and patients enrolled}

The first experience of domiciliary assistance for patients affected by chronic respiratory illness dates back to the beginning of the 2000s. In 2006, a more structured experimentation has been instituted, in collaboration with the Regional Government. The service has been institutionalized in 2010.

Patients involved in the experimentation belong to the hospital district and Province; access criteria are related to their dependency on oxygen and ventilator and to the severity stadium of the illness. The structure enrolls one hundred patients as average. Each of them is assigned to a specific tutor nurse.

The organizational levers adopted to enhance a sustainable work system

Two major levers have been utilized to render the telemedicine-based service work system sustainable: (i) the empowerment of nurses and (ii) the involvement of the Call Center of the Technologic Service Provider for the provision of the service.

The empowerment of nurse

The nurses of the Hospital Respiratory Department play a pivotal role in patients' assistance, since they represent (i) the hospital interface for patients, (ii) the filter for hospital specialists in handling/signaling the emergency situations and (iii) the responsible for educating and training patients and/or caregivers. Within this scenario, nurses are very satisfied because they perceive that the telemedicine-based service would enhance their professionalism. This positive mood is witnessed by the increased number of applications received from other nurses who would like to join the service. The stricter relationship established between the nurse and the patient increases this latter satisfaction too. Patients, in fact, feel more safety, increase their quality of life and, most importantly, have the chance to comprehend their pathology better, assuming major autonomy in dealing with it.

Though the service is particularly appreciated, its organizational burden is high, since it requires that 3 nurses work on it full time, and that at least a specialist of the Hospital Respiratory Department is available to perform a second opinion when needed. 


\section{Involvement of the Call Center of the Technologic Service Provider}

The direct involvement of the Call Center allows the provision of a $24 \mathrm{~h}$ service, without asking the hospital team for an all-day-availability. Moreover, since data and phone calls always transit through the Technologic Service Provider network, every information is recorded and backed up, relieving hospitals by medic-legal responsibilities.

However, the possibility for patients to be connected with the personnel of the call center is considered a very delicate aspect. The possibility of harmful interferences (though limited by the presence of the online clinical record) and the uncertainties about the legal responsibilities of actions are, in facts, matters of concern.

Finally, the territorial facilities are rarely involved, and seldom GPs intervene.

A summary of how the utilized levers impact on the sustainable work system design principles to enhance an effective telemedicine-based service is reported above (Tab. 6).

\begin{tabular}{|c|c|c|}
\hline Coordination & \multicolumn{2}{|c|}{ (-) GPs are seldom involved } \\
\hline $\begin{array}{l}\text { Workload } \\
\text { distribution }\end{array}$ & $\begin{array}{l}\text { (+) the involvement of the nurses } \\
\text { introduces a filter in the service } \\
\text { delivery processes; } \\
(-) \text { the organizational burden for } \\
\text { nurses is high. }\end{array}$ & $\begin{array}{l}(+) \text { the involvement of the Call Center } \\
\text { guarantees a } 24 \text { h service without } \\
\text { asking hospital personnel for an all- } \\
\text { day-availability }\end{array}$ \\
\hline Competences & $\begin{array}{l}(+) \text { thanks to the direct and constant } \\
\text { relationship with the nurses, patients } \\
\text { and caregivers acquire a better and } \\
\text { more aware knowledge of how to } \\
\text { handle the pathology; } \\
(+) \text { nurses competences have been } \\
\text { empowered. }\end{array}$ & \\
\hline \multirow[t]{2}{*}{ Satisfaction } & $\begin{array}{l}(+) \text { nurses are satisfied because their } \\
\text { professionalism has been enhanced; } \\
(+) \text { patients and caregivers are } \\
\text { satisfied because they have a direct } \\
\text { and constant hospital interface } \\
\text { available. }\end{array}$ & $\begin{array}{l}(+) \text { the clinical staff has the chance to } \\
\text { monitor patients for } 24 \mathrm{~h} \text {, without } \\
\text { hospitalize them. }\end{array}$ \\
\hline & \multicolumn{2}{|c|}{$\begin{array}{l}(+) \text { the clinical staff has the chance to better follow up chronic patients, without } \\
\text { hospitalize them. }\end{array}$} \\
\hline
\end{tabular}

Table 6. Synthesis of the Case 4.

\subsection{Case 5}

The fifth project is provided by the Respiratory Department of a non teaching hospital of the Northern Italy (11 physicians, 3 therapists and 26 nurses; 20 beds).

The organization design: which services are provided and how

The main telemedicine-based services provided are two.

Telemonitoring: The staff of the LHA reaches the domicile of the patient and proceeds in recording a list of predefined parameters. The frequency of the visits depends on the health conditions of the patient (from once a week to once a day). Once data have been gathered, the LHA staff sends them via fax to the hospital unit of Domiciliary Respiratory Assistance (DRA), where the patient's tutor nurse verifies the patient's clinical conditions. In case of out-of-range parameters, or critical scenario highlighted by the LHA staff, the DRA nurse 
has the chance to contact the hospital physician for a second opinion. The specialist, on his/her hand, may decide to (i) contact the GP and ask him/her to perform a visit at domicile, (ii) contact the emergency service for an immediate intervention or (iii) hospitalize the patient.

Periodically, a nurse of the DRA and a hospital physician visit the patient at domicile to perform activities that go beyond the competencies of the staff of the LHA.

Teleconsulting: Each patient has the possibility to directly contact his/her DRA tutor nurse to receive an immediate consultation. The service is available from Monday to Friday, from 7.30 to 19.30 and on Saturday from 7.30 to 13.30 . On holy-days and during the night, the staff of the Respiratory Intensive Care Department of the hospital is available to handle patients' requests for teleconsultations.

Evolution of the service and patients enrolled

A first phase of the experimentation started in 1994; from the beginning of 1995, the service required the involvement of a lung specialist and a part-time nurse. In 2001, the service enhanced an extent of 175 patients per year. Since 2008, 4 nurses have been completely staffed on the service and they manage the whole service delivery autonomously. The patients involved in the service are now 160, and they are resident of the hospital district. Access criteria are related to the dependency of patients on the ventilator, being it partial (8 hours minimum) or continuous.

The organizational levers adopted to enhance a sustainable work system

Two major levers have been utilized to render the telemedicine-based service work system sustainable: (i) the empowerment of nurses and (ii) the definition of an inter-organizational business model.

The empowerment of nurses

The nurses of the Domiciliary Hospital Assistance have been delegated to be responsible for the provision of the telemedicine-based service. This decision has turned out being particularly effective, as it has been calculated that more than $80 \%$ of the requests posed by patients have been faced and solved without involving physicians. Because of this, nurses are satisfied with the service since they perceive their professionalism has been enhanced. The stricter relationship established between the nurse and the patient, moreover, increases this latter satisfaction too.

Though the service is particularly appreciated, nurses highlighted ulterior personnel should be involved in its provision, especially if a wider amount of patients will be enrolled. Thus far, in fact, the organizational burden is high: the 4 nurses receive an average of 50 calls per day, while busy with the training activities too.

The definition of an inter-organizational business model

The continuity of care assured by the service is one of its main critical success factors, since it involves in a very effective way specialists, hospital and LHA staff, i.e. nurses, psychologists, social operators and technicians. In particular, the hospital team is responsible for tele-monitoring the patients' clinical conditions, and to intervene in case of out-of-range parameters. The LHA staff, on its hand, visits the patients' domicile, monitors the effective suitability of the caregiver, and identifies eventual conflicting situations within the patient's family. 
Patients widely appreciate the possibility to interact with a complete clinical team, composed not only by hospital specialists, but also by LHA staff, dedicated for example to psychological care.

\begin{tabular}{|c|c|c|}
\hline Coordination & & $\begin{array}{l}(+) \text { the structured coordination } \\
\text { between territorial services and } \\
\text { hospital enables a wider contact } \\
\text { between the clinical team and the } \\
\text { territory }\end{array}$ \\
\hline$\frac{\text { Workload }}{\text { distribution }}$ & $\begin{array}{l}(+) \text { nurses demonstrated their } \\
\text { potentialities for being autonomous in } \\
\text { taking most of the decisions; } \\
(-) \text { the organizational burden for nurses } \\
\text { is high. }\end{array}$ & $\begin{array}{l}(+) \text { the structured business model } \\
\text { between LHA and hospital enables a } \\
\text { better distribution of tasks and } \\
\text { responsibilities }\end{array}$ \\
\hline Competences & $\begin{array}{l}(+) \text { thanks to the direct and constant } \\
\text { relationship with the nurses, patients } \\
\text { and caregivers acquire a better and } \\
\text { more aware knowledge of how to } \\
\text { handle the pathology } \\
(+) \text { nurses competences have been } \\
\text { empowered }\end{array}$ & \\
\hline \multirow[t]{2}{*}{ Satisfaction } & $\begin{array}{l}(+) \text { nurses are satisfied because their } \\
\text { professionalism has been enhanced; } \\
(+) \text { patients and caregivers are satisfied } \\
\text { because they have a direct and constant } \\
\text { hospital interface available }\end{array}$ & $\begin{array}{l}(+) \text { patients widely appreciated the } \\
\text { various and completed competences } \\
\text { rendered available from the } \\
\text { heterogeneous clinical team }\end{array}$ \\
\hline & \multicolumn{2}{|c|}{$\begin{array}{l}(+) \text { the clinical staff has the chance to better follow up chronic patients, without } \\
\text { hospitalize them. }\end{array}$} \\
\hline
\end{tabular}

Table 7. Synthesis of the Case 5.

Moreover, great coordination is contemplated among the DRA and the Hospital Emergency Department. Each patient, in facts, is provided with an informative outline which sums up the main clinical conditions of the patients. In this way the emergency intervention is facilitated since information on the plan of care in progress are available for operators. To further increase the degree of collaboration with the emergency service, the nurses prepare and update periodically an informative prospect with a list of the most precarious patients in mechanical ventilation: next to the name and address of every patient, it is indicated the pathology from which it suffers, the model of ventilator employed, the maximum autonomy of batteries, while a colored light (green, yellow, red) indicates the priority of intervention in case of prolonged electric black out. In this way, in case of request of emergency intervention or electric black out that causes the deactivation of the respiratory and of other electrical devices, the emergency operators are able to plan the order of intervention effectively, according to the specific patients' needs.

This high level of coordination is very helpful to face the main sources of risks of care at distance, which are prolonged electrical blackouts, caregiver's stress, infections, scarce ethical and welfare continuity. The possibility to create shared and well managed plans and the presence of common guidelines is very helpful in keeping all these aspects under control. 
To sum up, a synthesis of how the above explained levers contributed to the enhancement of a sustainable work system is reported above (Tab. 7).

\subsection{Case 6}

The sixth project is provided by the Respiratory Department of a non teaching hospital of the Northern Italy (6 physicians, 6 technicians of physiopathology, 1 molecular biologists, 1 technician biologist, 25 nurses, 2 psychologists; 16 beds of ordinary hospitalization, 2 beds for monitoring in breath therapy).

The organization design: which services are provided and how

The main provided telemedicine-based services are two.

Telemonitoring: a technologic device records the patients' main vital parameters, and sends them to the hospital. Daily the physicians or the nurses read the outlines and evaluate the patients' health conditions. If they detect out-of-range parameters, the clinician contacts the patient to evaluate a potential necessity to perform an emergency intervention. In some cases the specialist contacts the GP, asking him to perform a domicile visit.

Teleconsulting: the hospital Unit is equipped with an alarm that is activated when (i) the software detects an out-of-range parameter, or (ii) the patient contacts the Unit because of a perceived worsening of his/her clinical conditions. When the alarm rings, a nurse or a specialist reaches the office where computers are located and checks the outlines. If necessary, a telephone call to the patient is performed. The service is active during the weekdays, on working hours.

Evolution of the service and patients enrolled

The service is ongoing since 1994, when it was institutionalized as Home Hospitalization $(\mathrm{HH})$. The patients enrolled are 240 as average, 70 of which in intensive or continuous ventilation. Access criteria deal with a serious respiratory insufficiency and, with it, oxygen therapy in continuous/partial ventilation.

Enrolled patients live within the hospital district.

The organizational levers adopted to enhance a sustainable work system

The major lever utilized to render the work system sustainable is the empowerment of nurses.

The empowerment of nurses

Nurses play a pivotal role in the service delivery, since they manage, in accordance with the physicians, the patients care plan, are in charge of the training of patients and, most importantly, are responsible to make patients able to enhance a satisfactory level of comprehensiveness and awareness with respect to their pathology. This task increases nurses' responsibilities and professionalism, and it is source of great satisfaction for them.

Not only medical professionalisms, but even patients are very satisfied with this service. In particular, a survey distributed among patients highlighted that the perceived quality of life widely increased after the enrollment: $17 \%$ of them said to have feelings about having made progress toward recovery after three years from their enrollment into the service. It represents a strong signal of the satisfaction of patients.

Finally, the level of coordination with the GPs is considerable, since they play an active role in the service by performing interventions at domicile when needed. 
A summary of how the utilized lever impacts on the sustainable work system design principles to enhance an effective telemedicine-based service is reported above (Tab 8).

\begin{tabular}{|l|l|}
\hline Coordination & $(+)$ GPs are actively involved in the service delivery \\
\hline$\underline{\text { Workload }}$ & $\begin{array}{l}(+) \text { patients has a more aware and appropriate access to care; } \\
(+) \text { the involvement of the nurses keeps the workload burden affordable. }\end{array}$ \\
\hline$\underline{\text { Competences }}$ & $\begin{array}{l}(+) \text { nurses competences are enhanced; } \\
(+) \text { thanks to the direct and constant relationship with the nurses and physicians, } \\
\text { patients and caregivers acquire a better and more aware knowledge of how to } \\
\text { handle the pathology patients and caregivers acquire a better and more aware } \\
\text { knowledge about how to handle the pathology. }\end{array}$ \\
\hline$\underline{\text { Satisfaction }}$ & $\begin{array}{l}(+) \text { the clinical staff has the chance to better follow up chronic patients without } \\
\text { hospitalize them; } \\
(+) \text { nurses are satisfied because their professionalism has been enhanced; } \\
(+) \text { patients and caregivers are satisfied because acquire a better and more aware } \\
\text { knowledge of how to handle the pathology. }\end{array}$ \\
\hline
\end{tabular}

Table 8. Synthesis of the Case 6.

\section{Discussion and conclusions}

The discussion and conclusions are organized as follows. First, evidence gathered through the analysis of the sample of selected telemedicine-based services is shown. Second, remarks concerning the applicability and the meaningfulness of the adopted conceptual framework are reported. Finally, the managerial implications and the directions for future researches are proposed.

\section{The explanatory results}

Drawing on our results, three main levers emerge as keys for enhancing the sustainability of the peculiar work system "telemedicine-based service". They are (i) the formalization of a clear and agreed business model between the hospital unit and the Local Health Agency (LHA); (ii) the involvement of a call center for the provision of the service and (iii) the empowerment of nurses. In other terms, three distinct enabling levers have been identified for the enhancement of sustainable work system's design principles (see Tab. 9).

Some of these retrieved levers have a specific impact on one of the design principle. The definition of a business model between the hospital unit and the LHA (see case 1 e case 5), for example, enables a coordination between the clinical team and the territory which is much tighter than the one enhanced through other levers.

Drawing on the retrieved levers, moreover, it is highlighted that the empowerment of nurses is the most effective for the enhancement of a sustainable work system. This latter, in fact, maximizes the positive impacts on sustainable work system's design principles. In particular, it underpins the institution of new professionals' boundaries and of new team practices, rendering the team the key organizational structure. Although the need to reshape the professionals' boundaries (mainly physicians' and nurses') has been highlighted in all the analyzed studies, however, it impacts differently on the specific professionals' workload: in some cases (case 3 and case 6 ) the division of work is considered sustainable, while in others (case 4 and case 5) nurses denounced to have been working to a too tight schedule. 


\begin{tabular}{|c|c|c|c|}
\hline The main levers: & $\begin{array}{l}\text { Definition of a } \\
\text { business model } \\
\text { between the hospital } \\
\text { unit and the LHA }\end{array}$ & $\begin{array}{l}\text { Involvement of a Call } \\
\text { Center for the } \\
\text { provision of the } \\
\text { service }\end{array}$ & $\begin{array}{c}\text { Empowerment of } \\
\text { nurses }\end{array}$ \\
\hline Coordination & $\begin{array}{l}(+) \text { the structured } \\
\text { coordination between } \\
\text { the LHA staff and the } \\
\text { hospital team enables a } \\
\text { wider collaboration } \\
\text { between the clinical team } \\
\text { and the territory (case } 1 \text { e } \\
\text { case } 5) \text {. }\end{array}$ & & \\
\hline $\begin{array}{l}\text { Workload } \\
\text { distribution }\end{array}$ & $\begin{array}{l}(+) \text { the definition of a } \\
\text { structured business } \\
\text { model between LHA and } \\
\text { hospital enables a better } \\
\text { distribution of tasks and } \\
\text { responsibilities } \\
\text { (case } 1 \text { and 5); } \\
(-) \text { the enrollment of a } \\
\text { limited number of } \\
\text { patients is key to } \\
\text { maintain the work } \\
\text { system sustainable } \\
\text { (case } 1 \text { ). }\end{array}$ & $\begin{array}{l}(+) \text { the involvement of } \\
\text { the Call Center keeps the } \\
\text { workload burden } \\
\text { affordable (case } 2) ; \\
(+) \text { the involvement of } \\
\text { the Call Center } \\
\text { guarantees a } 24 \text { h service } \\
\text { without asking hospital } \\
\text { personnel for an all-day- } \\
\text { availability (case } 4) \text {. }\end{array}$ & $\begin{array}{l}(+) \text { the involvement of } \\
\text { the nurses keeps the } \\
\text { workload burden } \\
\text { affordable (case } 3 \text { and } \\
\text { case } 6) \text {; } \\
(+) \text { patients acquire a } \\
\text { more aware access to } \\
\text { hospitals (case } 3 \text { and case } \\
6) \text {. } \\
(+) \text { the involvement of } \\
\text { the nurses introduces a } \\
\text { filter in the service } \\
\text { delivery processes (case } \\
4) ; \\
(+) \text { nurses demonstrated } \\
\text { their potentialities for } \\
\text { being autonomous in } \\
\text { taking most of the } \\
\text { decisions (case } 5 \text { ). } \\
(-) \text { the organizational } \\
\text { burden for nurses is high } \\
\text { (case } 4 \text { and case } 5 \text { ). }\end{array}$ \\
\hline Competences & & & $\begin{array}{l}(+) \text { nurses widely } \\
\text { widened their } \\
\text { competences (case } 3 \text {, case } \\
4 \text {, case } 5 \text { and case } 6) ;\end{array}$ \\
\hline$\underline{\text { Satisfaction }}$ & $\begin{array}{l}\text { (-) nurses are not } \\
\text { satisfied because no new } \\
\text { incentives have been } \\
\text { introduced, although } \\
\text { they are partly involved } \\
\text { in the service delivery } \\
\text { (case 1); } \\
(+) \text { patients widely } \\
\text { appreciated the various } \\
\text { and completed } \\
\text { competences rendered } \\
\text { available from the } \\
\text { heterogeneous clinical } \\
\text { team (case 5). }\end{array}$ & $\begin{array}{l}(+) \text { the clinical staff has } \\
\text { the chance to monitor } \\
\text { patients for } 24 \mathrm{~h} \text {, without } \\
\text { hospitalize them (case } 4) \text {; } \\
(-) \text { the involvement of } \\
\text { Call Center makes some } \\
\text { patients uncomfortable } \\
\text { since they perceive the } \\
\text { personal relationship } \\
\text { with the specialist was } \\
\text { diminishing (case } 2 \text { ). }\end{array}$ & $\begin{array}{l}(+) \text { patients and } \\
\text { caregivers are satisfied } \\
\text { because they avoid } \\
\text { unnecessary trips to } \\
\text { hospitals (case } 3) ;(+) \\
\text { nurses are satisfied } \\
\text { because their } \\
\text { professionalism has been } \\
\text { enhanced (case } 3, \text { case } 4 \text {, } \\
\text { case } 5 \text { and case } 6) \text {. }\end{array}$ \\
\hline
\end{tabular}

Table 9. Synthesis of data 


\section{Theoretical implications}

This study confirms that both the agility model framework and the concept of sustainable work system are useful bases to support policy makers to design and introduce effective telemedicine-based services. The conceptualisation of this model to the specific context of telemedicine-based services allowed us to analyze the innovation of previous practice as a whole, and helped us to identify and discuss a list of critical success factors that are usually overlooked or underestimated.

\section{Managerial implications and directions for future researches}

Two major managerial implications about the introduction of telemedicine-based services can be remarked. First, the relationships and the balances both within the hospital team and between hospitals and the territorial healthcare facilities potentially change. Accordingly, not only intra-hospital but even inter- healthcare-providers processes get modified. Second, non-clinical members (i.e. patients and suppliers) become part of the clinical team, and start playing an active role within routine healthcare delivery processes. Accordingly, a strong, not only operational, but even cultural challenge needs to be enhanced to introduce an effective telemedicine-based service. Professionals and professionals' associations need to be aware of it. However, since healthcare is a highlyregulated context, these organizational and cultural changes need to be accompanied by a regulator's intervention.

Because of these implications, we believe that the identification of the design principles that might promote the sustainability over time of a telemedicine-based service is a relevant field of research and there is need for further investigation by both academicians and healthcare practitioners. In particular, we believe that three main directions for future researchers might be relevant.

First, our analysis of the six experiences formalizes three main leverages that might help the design of effective telemedicine-based services. The role and relevance of these leverages should be deepened and verified by means of further research. The understanding of their factual contribution to sustainability would have significant impacts on policy makers and healthcare professionals. For instance, the empowerment of nurses obliges wide and severe debates about how to reshape the command (and responsibility) chain in healthcare. The institutionalization of regional public vs. private call centers is a controversial issue. On the one hand, there is a need for efficiency and thus a large-scale provider should be preferred, on the other hand, physicians and nurses arise concerns about the externalization beyond the hospital walls of such a delicate service. An in-depth investigation of pros and cons should be thus recommended.

Second, the ways by means of which the command (and responsibility) chain is reshaped among doctors, nurses, healthcare assistants and technicians should be investigated in order to enhance our current understanding of how promoting changes in healthcare. Two useful perspectives for this research stream might be, on the one hand, the one provided by Abbott (1988) with respect to the clash among different professions, or, on the other hand, the one provided by Carroll and Edmondson (2002) about the relevance of a context of psychological safety to facilitate change and improve organizational learning.

Finally, our study and results refer to the specific context of telemedicine-based services for patients affected by COPD in Italy. Thus there are at least two contingencies that should be 
explored by further research to understand the generalizability of our results. On the one hand, telemedicine-based services for patients affected by other pathologies (e.g. chronic heart disease) should be investigated to collect evidence about how the peculiarities of a specific pathology could affect the design of the service. On the other hand, we know that healthcare delivery is largely affected by institutional contingencies. In this view, it would be value adding to explore to what extent our results (and successful experiences) could be translated in other Countries, such as US or UK.

\section{Acknowledgements}

This research was supported by grants from the Italian Minister of Health Care and the Health Care Counsellorship of the Lombardy region within the project "Progetto Strategico BPCO". The authors gratefully acknowledge the interviewees, Federica Segato for her fundamental support and the authors of comments on previous versions of this manuscript.

\section{References}

Aas, M. (2001). A qualitative study of the organizational consequences of telemedicine. Telemedicine journal and e-Health, 14, 9, (February 2001), 18-26.

Abbott, A. (1988). A system of professions. The university of Chicago Press. London.

Alter S. (2004). A work system view of DSS in its fourth decade. Decision Support Systems, 38, 3, (December 2004), 319- 327.

de Bont, A. \& Bal, R. (2008). Telemedicine in interdisciplinary work practices: on an IT system that met the criteria for success set out by its sponsors, yet failed to become part of every-day clinical routine. BMC Medical Informatics and Decision Making, 8, 47, (October 2008).

Carroll, J.S. \& Edmonson, A.C. (2002). Leading organizational learning in Health Care. Qualitaty and Safety in Healthcare, 11, (January 2002), 51-56.

Docherty, P.; Forslin, J. \& Shani A.B. (2002). Creating sustainable work systems. Routledge, London.

Docherty, P. \& Shani A.B. (2008). Learning mechanisms as means and ends in collaborative management research. In Handbook of collaborative management research Shani ,A. B.; Mohrman, S. A.; Pasmore, W. A.; Stymne, B. N. \& Adler, (163-182), Sage, Thousand Oaks, CA.

Eisenhardt, K. M. (1989). Building theories from case study research. Academy of Management Review, 14, 4, (October 1989), 532-550.

Forbes, A. \& While, A. (2009). The nursing contribution to chronic disease management: a discussion paper. International Journal of Nursing Studies. 46, 1, (January 2009), 120131.

Gagnon, M.; Legare, F.; Fortin, J.; Lamothe, L.; Labrecque, M. \& Duplantie, J. (2008). An integrated strategy of knowledge application for optimal e-health implementation: a multi-method study protocol. BMC Medical Informatics and Decision Making, 8, 17, (April 2008).

Galbraith, J.R. (2005). Designing the customer-centric organization: A guide to strategy structure, and processes.Jossey-Bass, San Francisco, CA. 
Gilbert, C. G. (2005). Unbundling the structure of inertia: Resource versus routine rigidity. Academy of Management Journal, 48, 5, 741-763.

Hibbert, D.; Mair, FS.; May, CR.; Boland, A.; O'Connor, J.; Capewell, S. \& Angus, RM. (2004). Health professionals' responses to the introduction of a home telehealth service. Journal of Telemedicine and Telecare, 10. 4, (August 2004), 226-230.

Huber, G. P. \& Power D. J. (1985). Retrospective reports of strategic-level managers: Guidelines for increasing their accuracy. Strategic Management Journal, 6, 2, (April/June, 1985), 171-180.

Institute of Medicine (IOM) (2008). Knowing what works: a roadmap for the nation. (January 2008).

Kohn A. (1993). Why Incentive Plans Cannot Work. Harvard Business Review. (SeptemberOctober 1993), 54-63.

Lehoux, P.; Sicotte, C.; Denis, JL.; Berg, M. \& Lacroix, A. (2002), The theory of use behind telemedicine: how compatible with physicians' clinical routines?". Social Science $\mathcal{E}$ Medicine, 54, 6, (March 2002), 889-904.

Lijphart, A. (1971). Comparative politics and comparative methods. The American Political Science review, 65, 3, 682-693.

Miller, C. C.; Cardinal, L. B. \& Glick W. H. (1997). Retrospective reports in organizational research: A reexamination of recent evidence. Academia of Management Journal, 40, 1, (February 1997), 189-204.

Mitroff, I. I. (1972). The myth of objectivity or why science needs a new psychology of science. Management Science, 18, 10, (June 1972), 613-618.

Nicolini, D. (2006). The work to make telemedicine work: A social and articulative view. Social Science E Medicine,. 62, 11, (June 2006), 2754-2767.

Obstfelder, A.; Engeseth, K.H. \& Wynn, R. (2007). Characteristics of successfully implemented telemedical applications. Implementation Science, 2, 25, (July 2007).

Pasmore, W. A.; Woodman, R. W. \& Simmons, A. L. (2008). Toward a more rigorous, reflective, and relevant science of collaborative management research. In Handbook of collaborative management research Shani, A. B.; Mohrman, S. A.; Pasmore, W. A.; Stymne, B. N. \& Adler, (567-582), Sage, Thousand Oaks, CA.

Patton, M. Q. (2002). Qualitative Research and Evaluation Methods, 3rd ed.Sage Publications, Thousand Oaks, CA.

Timmermans, S. \& Berg, M. (2003). The practice of medical technology. Sociology of Health $\mathcal{E}$ Illness, 25, 3, (April 2003), 97-114.

Whitten, P.; Holtz, B. \& Nguyen, L. (2010) Keys to a successful and sustainable telemedicine program. International Journal of Technology Assessment in Health Care, 26, 2, (April 2010), 211-216.

Worley, C. \& Lawler, E. (2010). Built to Change Organizations and Responsible Progress: Twin Pillars of Sustainable Success, in Research in Organizational Change and Development (Volume 18), Woodman, R.; Pasmore, W. \& Shani, A.B. Emerald Group Publishing Limited. 
Wynia M.K. (2009). The Risks of Rewards in Health Care: how pay-for-performance could threaten, or bolster, medical professionalism. Journal of General Internal Medicine, 24, 7, (July 2009), 884-887.

Yin, R. (1984) Case Study research: design and method, Sage, Thousand Oaks, California.

Zajtchuk, J.T. \& Zajtchuk, R. (1996). Strategy for Medical Readiness: Transition to the Digital Age. Telemedicine Journal, 2, 3, (Fall 1996), 179-186.

www.goldcopd.it 


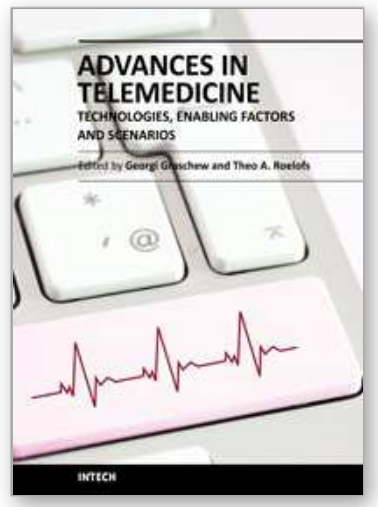

\author{
Advances in Telemedicine: Technologies, Enabling Factors and \\ Scenarios \\ Edited by Prof. Georgi Graschew
}

ISBN 978-953-307-159-6

Hard cover, 412 pages

Publisher InTech

Published online 16, March, 2011

Published in print edition March, 2011

Innovative developments in information and communication technologies (ICT) irrevocably change our lives and enable new possibilities for society. Telemedicine, which can be defined as novel ICT-enabled medical services that help to overcome classical barriers in space and time, definitely profits from this trend. Through Telemedicine patients can access medical expertise that may not be available at the patient's site. Telemedicine services can range from simply sending a fax message to a colleague to the use of broadband networks with multimodal video- and data streaming for second opinioning as well as medical telepresence. Telemedicine is more and more evolving into a multidisciplinary approach. This book project "Advances in Telemedicine" has been conceived to reflect this broad view and therefore has been split into two volumes, each covering specific themes: Volume 1: Technologies, Enabling Factors and Scenarios; Volume 2: Applications in Various Medical Disciplines and Geographical Regions. The current Volume 1 is structured into the following thematic sections: Fundamental Technologies; Applied Technologies; Enabling Factors; Scenarios.

\title{
How to reference
}

In order to correctly reference this scholarly work, feel free to copy and paste the following:

Laura Bartoli, Emanuele Lettieri and Cristina Masella (2011). Innovative Healthcare Delivery: the Quest for Effective Telemedicine-based Services, Advances in Telemedicine: Technologies, Enabling Factors and Scenarios, Prof. Georgi Graschew (Ed.), ISBN: 978-953-307-159-6, InTech, Available from: http://www.intechopen.com/books/advances-in-telemedicine-technologies-enabling-factors-andscenarios/innovative-healthcare-delivery-the-quest-for-effective-telemedicine-based-services

\section{INTECH}

open science | open minds

\section{InTech Europe}

University Campus STeP Ri

Slavka Krautzeka 83/A

51000 Rijeka, Croatia

Phone: +385 (51) 770447

Fax: +385 (51) 686166

www.intechopen.com

\section{InTech China}

Unit 405, Office Block, Hotel Equatorial Shanghai

No.65, Yan An Road (West), Shanghai, 200040, China

中国上海市延安西路 65 号上海国际贵都大饭店办公楼 405 单元

Phone: +86-21-62489820

Fax: +86-21-62489821 
(C) 2011 The Author(s). Licensee IntechOpen. This chapter is distributed under the terms of the Creative Commons Attribution-NonCommercialShareAlike-3.0 License, which permits use, distribution and reproduction for non-commercial purposes, provided the original is properly cited and derivative works building on this content are distributed under the same license. 